\title{
'Leadership' in lockdown
}

\author{
Business coach Chris Barrow on the failure in the private sector and what must \\ be done about it
}

I 's the back end of a week in which lawyers, senior counsel, indemnifiers, suppliers, regulators, associations, academics and home nation CDOs have made great efforts to either clarify, challenge or confirm, frankly leaving most independent practice owners more confused than ever.

What I've heard from practitioners this week can best be described as frustration, fear, uncertainty, anger and exasperation.

It's all very well sitting in a salaried ivory tower and pontificating, but when you are the owner of a small business you have a leadership responsibility to multiple communities. They are all looking to you for guidance and, as I've discovered recently, you dare not have a bad day - because your emotion is contagious.

Along the way, many owners in private practice have been shouldering the financial burden of their furloughed businesses and attempting to offer support, both emotionally and sometimes practically to team members and self-employed clinicians who have been at best confused and sometimes terrified.

As soon as lockdown started, the first important message to my dental clients was to 'keep communicating' with all the communities I list above. The quality and the quantity of that communication has clearly differentiated the 'winners' and 'losers' in the lockdown period.

My second message was that 'people will remember the things you did and the way that you did them. Whether it is silence or noise, good or bad, people will not forget how you showed up.

My third message was to keep the message confident, no matter how hard things become.

I have always defined leadership as the combination of the following attributes:

$\rightarrow$ To communicate a clear vision - knowing

where we are going, why we are going there and how we intend to do it

$\rightarrow$ To be an example of the standards of performance and behaviour that you expect from those around you - people will follow your lead and that is a 365/24 burden that the leader must bear

$\rightarrow$ To create environments in which people can choose to become self-motivated (think Henry V at Agincourt - think Churchill)

$\rightarrow$ To understand what makes people tick and to be prepared to 'walk the floor'

$\rightarrow$ To be an effective delegator, focusing on your own unique abilities and learning to eliminate, automate or delegate 'everything else'.

So how have our dental 'leaders' appeared during these worrying weeks?

I mentioned earlier the memories that are being made right now.

Here are some (but not all) of the negative emotions I will remember about lockdown:

$\rightarrow$ The insensitivity of the GDC is contributing nothing to the current crisis other than reminding everyone that their ARF wasn't going to reduce

$\rightarrow$ The vacuum of leadership for the private sector from the office of the CDO

$\rightarrow$ The confusion created by the CQC in not clarifying their position in response to private practitioners attempting to help patients in need of face to face urgent care;

$\rightarrow$ The evasiveness of many business interruption insurance providers when the proverbial hit the fan

$\rightarrow$ The confusion created by the banking community in their early contradictory responses to CBILs and Bounce Back Loans

$\rightarrow$ The tardiness of NHSE in establishing levels of abatement and the accurate division of finances and people for redeployment

$\rightarrow$ The indifference of some furloughed team members when invited to training in lockdown and maintaining team spirit

$\rightarrow$ The bewilderment of some self-employed clinicians, who seem to be in denial that dentistry 2.0 will affect their capacity to work and earn $\rightarrow$ The pettiness of a minority of owners who have manipulated teams and clinicians to maximise personal financial gain.

Before you lose hope, however, all is not dark. Here are some (but not all) of the positive emotions I will remember about lockdown:

$\rightarrow$ The quantity and quality of communication from the BDA throughout

$\rightarrow$ The relative speed with which many of the other 'home nations' CDOs have spelled out 'next steps' to their communities

$\rightarrow$ The resources that many manufacturers, distributors and service providers on the supply side have made available, free of charge, through webinars, other live broadcasts and downloads, to educate, inform and entertain the ownership community

$\rightarrow$ The camaraderie that has grown in the independent sector through many spontaneous associations, groups and forums - I truly believe that the private sector has never been so united

$\rightarrow$ The loyalty of teams and patients who have supported either by taking part in training or simply maintaining their plan payments

$\rightarrow$ The resilience of so many practice owners, who are determined to see this through, to weather the storms of the return to work phase and to gradually restore services to their patients, security to their teams, solvency for their families, as well as safety for all.

When we tell our grandchildren about COVID-19, I'm sure many of the emotions we are feeling today will have been wiped from our memories - as survivors we are wired that way.

Some feelings, however, will run deeper, and the winners and losers in leadership over recent weeks have made an indelible impression. I believe that independent practitioners, once the dust has settled, should be asking very serious questions about from whom and where their future leadership will arise. The present structures and personalities have largely failed them.

Once we have put this terrible pandemic behind us, questions must be asked about the future of our leadership. • 